\title{
Utilização de nutrientes de dietas contendo mananoligossacarídeo elou complexo enzimático para frangos de corte ${ }^{1,2}$
}

\author{
Maria Cristina de Oliveira ${ }^{3}$, Luciana Cardoso Cancherini ${ }^{4}$, Rodrigo Antônio Gravena ${ }^{5}$, Pricila \\ Vetrano Rizzo ${ }^{5}$, Vera Maria Barbosa de Moraes $^{5}$
}

\footnotetext{
1 Parte da tese de Doutorado da primeira autora.

2 Pesquisa financiada pela Fundação de Amparo à Pesquisa do Estado de São Paulo (FAPESP), Fundação para o Desenvolvimento da Unesp (FUNDUNESP) e Alltech do Brasil Agroindustrial Ltda

3 Faculdade de Medicina Veterinária - Universidade de Rio Verde, Rio Verde, GO.

${ }^{4}$ Departamento de Zootecnia - Universidade do Estado de Mato Grosso, Pontes e Lacerda, MT.

${ }^{5}$ Faculdade de Ciências Agrárias e Veterinária - UNESP, Jaboticabal, SP.
}

RESUMO - Avaliaram-se a digestibilidade ileal e a retenção de alguns nutrientes e os valores de energia de dietas contendo mananoligossacarídeo (MOS) e/ou complexo enzimático (CE) para frangos de corte. Foram utilizadas 275 aves em delineamento em blocos ao acaso e arranjo fatorial $2 \times 2+1$, com dois níveis de MOS (0 e 0,1\%), dois níveis de complexo enzimático ( 0 e $0,05 \%)$ e uma dieta controle positivo com antibióticos. O óxido crômico $(0,5 \%)$ foi adicionado às dietas para estimativa do fator de indigestibilidade. O experimento teve início quando as aves completaram 13 dias de idade; a coleta de excretas foi realizada do $20^{0}$ ao $22^{0}$ dia e a de digesta, no $23^{0}$ dia de idade das aves. A interação MOS $\times$ CE foi significativa para a retenção de PB e P e de energia metabolizável aparente (EMA), cujos valores foram maiores nas dietas com MOS e CE. A inclusão do CE melhorou a retenção de MS e os coeficientes de digestibilidade ileal de MS, PB, Ca e P na retenção de cálcio e nos valores de energia digestível com a inclusão de mananoligossacarídeo. Os coeficientes de digestibilidade ileal da MS, a retenção de MS, PB, Ca e P e os valores de energia digestível e de EMA das dietas contendo MOS e/ou CE foram superiores aos obtidos com a dieta contendo antibióticos.

Palavras-chave: aditivos, enzimas, prebiótico, valor nutritivo

\section{Nutrients utilization from diets containing mannan oligosaccharides and/or enzymatic complex for broilers}

\begin{abstract}
The ileal digestibility and retention of some nutrients and the energy content were evaluated in diets for broilers containing mannan oligosaccharides (MOS) and/or enzymatic complex (EC). Two hundred and seventy-five birds were used in a randomized complete block design, with factorial arrangement $(2 \times 2+1)$ of the treatments, with two MOS levels ( 0 and $0.1 \%$ ), two EC levels ( 0 and $0.05 \%)$ and a positive control diet with antibiotics. Chromic oxide (0.5\%) was added to the diets to estimate the indigestibility factor. The experiment started when the birds reached 13 days of age, the excreta collection was performed from the $20^{\text {th }}$ to the $22^{\text {nd }}$ day and the digesta collection at the $23^{\text {rd }}$ day of age of the birds. The interaction MOS x EC was significant for CP and P retention and for apparent metabolizable energy (AME), whose values were higher in diets with MOS and EC. EC inclusion improved DM retention and there was an improvement on ileal digestibility coefficient of DM, CP, Ca and P, Ca retention, and digestible energy values due to MOS inclusion. Ileal digestibility coefficients of DM, and DM, CP, Ca and P retention, as well as AME values were higher in diets containing MOS and/or EC compared with the diets containing antibiotics.
\end{abstract}

Key Words: additives, enzymes, nutritive value, prebiotic

\section{Introdução}

O mananoligossacarídeo (MOS) pode melhorar a utilização de nutrientes da dieta porque atua na redução da carga de bactérias intestinais e aumenta a área de absorção da mucosa (Moran, 2004). A redução destas bactérias diminui a competição por nutrientes entre a microflora e o hospedeiro (Ferket et al., 2002). Entretanto, resultados de estudos anteriores não têm demonstrado influência positiva do MOS sobre a digestibilidade de PB e EE (Kumprecht \& Zobac, 1997) em frangos com ingestão de dietas contendo até $0,3 \%$ de MOS. Mais recentemente, Zdunczyk et al. (2004), em experimento com perus, avaliaram a digestibilidade da PB de dietas sem antimicrobiano e com flavomicina ou 
$1 \%$ de MOS e não notaram diferença nos resultados atribuída aos aditivos.

Os polissacarídeos não-amiláceos (PNA) são carboidratos que aumentam a viscosidade das dietas por sua capacidade de se ligar a grandes quantidades de água formando um gel viscoso (Santos Jr. et al., 2004), o que diminui a taxa de difusão de substratos e enzimas digestivas e impede suas interações na superfície da mucosa intestinal (Choct, 2001), levando ao comprometimento da digestão e da absorção de nutrientes. Em dietas à base de milho e farelo de soja, também existem PNA solúveis (10 a 25 g/kg MS) e várias ligações 1-3, 1-4- $\alpha$-D-glucano (1 a 8 g/kg MS) (García et al., 2003; Józefiak et al., 2004). Os PNA podem ser hidrolisados por enzimas produzidas pela microflora cecal ou pela suplementação de enzimas específicas às dietas.

A ingestão de nutrientes estimula o desenvolvimento do trato gastrintestinal da ave, mas a síntese limitada de enzimas pancreáticas durante os primeiros dias após a eclosão pode limitar seu crescimento (Noy \& Sklan, 1995; Uni et al., 1995) tornando efetiva a suplementação de enzimas exógenas, visto que a atividade destas enzimas é muito baixa em aves jovens (Kobayashi et al., 2002).

Esse experimento foi realizado com o objetivo de avaliar a digestibilidade ileal e retenção de alguns nutrientes e os valores energéticos de dietas contendo MOS e/ou complexo enzimático (CE) para frangos de corte.

\section{Material e Métodos}

Foram utilizados 275 pintos machos Cobb com 13 dias de idade, alojados em gaiolas de metabolismo equipadas com bebedouros e comedouros lineares. A duração do período experimental foi de dez dias (sete para adaptação às dietas experimentais e às gaiolas e três para coleta parcial de excretas).

O delineamento experimental foi em blocos ao acaso, alocados segundo a altura dos andares das gaiolas, em arranjo fatorial 2 × $2+1$, com dois níveis de $\operatorname{MOS}^{1}$ ( 0 e 0,1\%); dois níveis de $\mathrm{CE}^{2}$ ( 0 e $0,05 \%$ ) e uma dieta controle positivo (CP) com antibiótico (10 ppm de virginiamicina e 125 ppm de sulfato de colistina como promotores de crescimento e $51 \mathrm{ppm}$ de salinomicina como anticoccidiano), totalizando cinco tratamentos com cinco repetições de 11 aves. A dieta sem MOS, CE ou antibióticos foi considerada controle negativo.
A fitase $^{3}$ (atividade mínima de $250 \mathrm{U} / \mathrm{g}$ ) foi utilizada em todas as dietas, enquanto o nível de fósforo não-fítico foi de $0,38 \%$, correspondente a $85 \%$ das exigências da ave, segundo Rostagno et al. (2000). O CE, na forma líquida, continha as enzimas celulase, protease e $\alpha$-amilase e foi pré-misturado a $500 \mathrm{~g}$ de farelo de soja.

Até os 13 dias de idade, todas as aves receberam dieta (Tabela 1) e água à vontade. As rações isonutritivas não continham indicador, prebiótico ou enzimas e foram formuladas de acordo com Rostagno et al. (2000), exceto quanto aos níveis de EM e PB, que corresponderam a 98\% dos níveis recomendados pelos autores.

Até os 12 dias de idade, as aves foram criadas em galpão de frangos convencional, onde foram alimentadas com a dieta controle positivo à vontade. Ao $13^{0}$ dia de idade, as aves foram alojadas em gaiolas e passaram a receber as dietas dos respectivos tratamentos misturadas com $0,5 \%$ de óxido crômico $\left(\mathrm{Cr}_{2} \mathrm{O}_{3}\right)$. Dos 20 a 22 dias de idade, efetuou-se a coleta parcial de excretas, em intervalo de 12 horas. Para a coleta das amostras de excretas, foram selecionados seis locais na bandeja e coletada uma subamostra, que, posteriormente, foi acondicionada em saco plástico identificado. Aos 23 dias de idade, todas as aves de cada repetição foram sacrificadas por deslocamento cervical e imediatamente seccionadas para obtenção da digesta do íleo terminal, desde $4 \mathrm{~cm}$ antes da junção íleo-cecocólica até $20 \mathrm{~cm}$ em direção ao jejuno. Este segmento foi seccionado longitudinalmente e seu conteúdo retirado e acondicionado em recipiente com tampa. As digestas e das excretas coletadas foram identificadas, armazenadas em congelador e, em seguida, foram pré-secas em estufa de ventilação forçada a $65^{\circ} \mathrm{C}$ por 48 horas, sendo, posteriormente, moídas.

Todas as análises das excretas, das digestas e das dietas foram realizadas segundo metodologia descrita por Silva \& Queiroz (2002). Uma vez obtidos os resultados das análises laboratoriais das dietas, da digesta e das excretas, foram calculados os coeficientes de digestibilidade aparente ileal, e a retenção de MS, PB, Ca e P e os valores de energia digestível (ED) e metabolizável aparente (EMA), com base nos níveis de cromo das dietas, das digestas e das excretas e no fator de indigestibilidade, como descrito por Dilger et al. (2004).

Os resultados do fatorial MOS x CE foram submetidos à análise de variância por meio do programa SAEG (UFV, 2001) e, quando houve interação significativa dos fatores, a comparação entre as médias foi realizada pelo teste Tukey.

\footnotetext{
1,2 Bio-Mos e Allzyme Vegpro Líquido. Alltech do Brasil Agroindustrial Ltda. Araucária, PR.

3 Allzyme Phytase 2X. Alltech Inc. Nicholasville, KY. USA.
} 
Tabela 1 - Composição percentual das dietas experimentais

Table 1 - Percentage composition of the experimental diets

\begin{tabular}{|c|c|c|c|c|c|}
\hline \multirow[t]{2}{*}{$\begin{array}{l}\text { Ingrediente (kg) } \\
\text { Ingredient }\end{array}$} & \multicolumn{5}{|c|}{$\begin{array}{l}\text { Tratamento } \\
\text { Treatment }\end{array}$} \\
\hline & $\mathrm{CP}$ & $\mathrm{CN}$ & $\mathrm{CE}$ & MOS & $\mathrm{MOS}+\mathrm{CE}$ \\
\hline Farelo de soja (Soybean meal) & 34,34 & 34,34 & 34,34 & 34,34 & 34,34 \\
\hline Óleo de soja (Soybean oil) & 1,58 & 1,58 & 1,58 & 1,58 & 1,58 \\
\hline Fosfato bicálcico (Dicalcium phosphate) & 1,45 & 1,45 & 1,45 & 1,45 & 1,45 \\
\hline L-lisina 78,80\% (L-lysine 78.80\%) & 0,20 & 0,20 & 0,20 & 0,20 & 0,20 \\
\hline Sal (Salt) & 0,45 & 0,45 & 0,45 & 0,45 & 0,45 \\
\hline Fitase (Phytase) & 0,01 & 0,01 & 0,01 & 0,01 & 0,01 \\
\hline MOS (MOS) & - & - & - & 0,10 & 0,10 \\
\hline CE (EC) & - & - & 0,05 & - & 0,05 \\
\hline Caulim (Caolim) & 0,15 & 0,15 & 0,10 & 0,05 & - \\
\hline \multicolumn{6}{|l|}{$\begin{array}{l}\text { Composição calculada }{ }^{3} \\
\text { Calculated composition }\end{array}$} \\
\hline $\mathrm{PB}(C P)(\%)$ & 21,00 & 21,00 & 21,00 & 21,00 & 21,00 \\
\hline EM (ME) $(\mathrm{kcal} / \mathrm{kg})$ & 2.940 & 2.940 & 2.940 & 2.940 & 2.940 \\
\hline Ca $(\%)$ & 0,96 & 0,96 & 0,96 & 0,96 & 0,96 \\
\hline P total (Total P) (\%) & 0,61 & 0,61 & 0,61 & 0,61 & 0,61 \\
\hline P não-fítico (Nonphytate P) (\%) & 0,38 & 0,38 & 0,38 & 0,38 & 0,38 \\
\hline Lisina total (Total lysine) (\%) & 1,26 & 1,26 & 1,26 & 1,26 & 1,26 \\
\hline Metionina total (Total methionine) (\%) & 0,49 & 0,49 & 0,49 & 0,49 & 0,49 \\
\hline Metionina + cistina total (Total methionine+cystine) & 0,83 & 0,83 & 0,83 & 0,83 & 0,83 \\
\hline
\end{tabular}

$\mathrm{CP}=$ controle positivo (positive control), $\mathrm{CN}=$ controle negativo (negative control), $\mathrm{CE}=$ complexo enzimático (enzymatic complex), $\mathrm{MOS}=$ mananoligossacarídeo (mannan oligosaccharides).

${ }^{1}$ Cada kg contém (each kg contain): vit. A - 150.0000; vit. $\mathrm{D}_{3}-285.000 \mathrm{UI}$; vit. E - 1.350 mg; vit. $\mathrm{K}_{3}-230 \mathrm{mg} ;$ vit. $\mathrm{B}_{1}-115 \mathrm{mg}$; vit. $\mathrm{B}_{2}-1.150 \mathrm{mg}$; vit. $\mathrm{B}_{12}$ - $2.000 \mathrm{mcg}$; ácido nicotínico (nicotinic acid) - 4.800 mg; ácido pantotênico (pantothenic acid) - 1.240 mg; piridoxina (pyridoxine) - 230 mg; biotina (biotin) - 12 mg; ácido fólico (folic acid) - 115 mg; colina (choline) - 85 g; metionina (methionine) - 170 g; Fe - 6.300 mg; Cu - 9.400 mg; Mn - 9.400 mg; Zn - 7.819 mg; I - 160 mg; Se - 23 mg; antioxidante (antioxidant) - 20 g; promotor de crescimento (growth promoter) - 5,4 g; anticoccidiano (anticoccidial) - 6,4 g.

2 Semelhante a 1, exceto pela ausência de promotor de crescimento e anticoccidiano (as to 1, except for the growth promoter and anticoccidial that were absent).

${ }^{3}$ De acordo com (according to) Rostagno et al. (2000).

Para comparação entre as médias do fatorial e do tratamento controle positivo, aplicou-se o teste Dunnett, por meio do programa Statistica for Windows, versão 5.1, (Statsoft, 1995).

\section{Resultados e Discussão}

Não houve efeito $(\mathrm{P}>0,05)$ dos blocos sobre nenhum dos parâmetros avaliados. A interação MOS $\times$ CE foi significativa $(\mathrm{P}<0,01)$ para a retenção de $\mathrm{PB}$, que foi superior nas dietas contendo MOS e CE em comparação aos valores obtidos nos demais tratamentos (Tabela 2). A inclusão de CE melhorou a retenção de MS $(\mathrm{P}<0,002)$ e os coeficientes de digestibilidade ileal de $\mathrm{MS}(\mathrm{P}<0,001)$ e $\mathrm{PB}(\mathrm{P}<0,01)$, que foram superiores nas dietas suplementadas com MOS. A interação controle positivo $\times$ fatorial foi significativa $(\mathrm{P}<0,05)$ para o coeficiente de digestibilidade da MS e a retenção de MS e PB, observando-se que os valores obtidos com dietas contendo CE e/ou MOS foram superiores aos daquelas contendo antibióticos.
De modo geral, os aditivos utilizados melhoraram a utilização da MS e da PB. A fermentação intestinal do MOS resulta na produção de ácidos graxos de cadeia curta (AGCC) que acidificam o meio, reduzindo a presença de bactérias intestinais que proliferam em $\mathrm{pH}$ alcalino, como Salmonella e E. coli, e, conseqüentemente, diminui a competição por nutrientes entre bactérias intestinais e hospedeiro (Ferket et al., 2004). O complexo enzimático, ao promover a hidrólise dos PNA, aumenta a disponibilidade de nutrientes para absorção (Meng et al., 2004). Além disso, os PNA agem como barreira física impedindo ou diminuindo o acesso de enzimas endógenas aos nutrientes. Assim, não apenas a viscosidade interfere na digestibilidade, mas também a liberação de nutrientes ligados aos PNA, a secreção de enzimas endógenas e a atividade bacteriana no trato digestivo (Hong et al., 2002).

Resultados semelhantes foram obtidos por Rodrigues et al. (2003), Lyayi \& Davies (2005) e Meng et al. (2005) com a suplementação enzimática. Entretanto, Kirkpinar et al. (2004), ao testarem o uso de prebiótico e enzimas, e Zdunczyk 
Tabela 2 - Coeficientes de digestibilidade ileal e retenção da MS e PB de dietas contendo mananoligossacarídeo (MOS) e/ou complexo enzimático (CE)

Table 2 - $\quad$ Apparent ileal digestibility coefficient and retention of DM and CP of diets containing MOS and/or enzymatic complex (EC)

\begin{tabular}{|c|c|c|c|c|c|c|}
\hline & \multirow[t]{2}{*}{$\begin{array}{l}\mathrm{CP} \\
\mathrm{PC}\end{array}$} & \multirow[t]{2}{*}{$\begin{array}{l}\text { MOS } \\
\text { MOS }\end{array}$} & \multirow[t]{2}{*}{$\begin{array}{l}C E \\
E C\end{array}$} & \multicolumn{2}{|c|}{$\begin{array}{l}\text { Média } \\
\text { Mean }\end{array}$} & \multirow[t]{2}{*}{ CV (\%) } \\
\hline & & & & $\begin{array}{c}\text { Sem } \\
\text { Without }\end{array}$ & $\begin{array}{l}\text { Com } \\
\text { With }\end{array}$ & \\
\hline Coeficiente de digestitilidade ileal da MS (\%) & & Sem (Without) & 73,36 & $77,87^{*}$ & $75,61 \mathrm{~B}$ & \\
\hline \multirow[t]{2}{*}{ Apparent ileal digestibility coefficient of DM (\%) } & & Com (With) & $82,09 *$ & $81,96^{*}$ & $82,03 \mathrm{~A}$ & \\
\hline & 73,40 & Média (Mean) & 77,72 & 79,92 & & 3,13 \\
\hline Retenção MS (\%) & & Sem (Without) & 75,27 & $80,58 *$ & 77,93 & \\
\hline \multirow[t]{2}{*}{ DM retention (\%) } & & Com (With) & 76,12 & $81,18 *$ & 78,65 & \\
\hline & 73,60 & Média (Mean) & $75,70 \mathrm{~b}$ & $80,88 \mathrm{a}$ & & 3,73 \\
\hline Coeficiente de digestitilidade ileal de PB (\%) & & Sem (Without) & 82,52 & 84,89 & $83,70 \mathrm{~B}$ & \\
\hline \multirow[t]{2}{*}{ Apparent ileal digestibility coefficient of CP (\%) } & & Com (Without) & 88,02 & 88,83 & $88,42 \mathrm{~A}$ & \\
\hline & 85,68 & Média (Mean) & 85,27 & 86,86 & & 3,38 \\
\hline Retenção de PB (\%) & & Sem (Without) & $71,83 \mathrm{Aa}$ & $70,52 \mathrm{Ba}$ & 71,18 & \\
\hline \multirow[t]{2}{*}{ CP retention (\%) } & & Com (With) & $70,46 \mathrm{Ab}$ & $77,97 \mathrm{Aa}^{*}$ & 74,22 & \\
\hline & 66,52 & Média (Mean) & 71,15 & 74,24 & & 4,22 \\
\hline
\end{tabular}

$\mathrm{CP}=$ controle positivo $(\mathrm{PC}=$ positive control).

Médias seguidas de letras diferentes minúsculas e maiúsculas nas linhas e colunas, respectivamente, diferem pelo teste Tukey.

*Difere do tratamento controle positivo pelo teste Dunnett.

Means followed by different small and capital letters in rows and columns, respectively, differ by Tukey test.

${ }^{*}$ Differ from positive control treatment by Dunnett test.

et al. (2004), ao utilizarem 1\% de MOS nas dietas, não detectaram diferenças nos coeficientes de digestibilidade total da MS e PB, respectivamente.

A interação MOS $\times$ CE $(\mathrm{P}<0,03)$ foi significativa para EMA (Tabela 3), de modo que os valores obtidos em aves alimentadas com dietas contendo os dois aditivos foram superiores aos encontrados nos demais tratamentos e os valores de energia digestível foram superiores $(\mathrm{P}<0,001)$ em 7,44 e 7,78\% em dietas suplementadas com MOS. A interação controle positivo $\times$ fatorial foi significativa para $\operatorname{ED}(\mathrm{P}<0,001)$ e EMA $(\mathrm{P}<0,05)$. Em comparação aos obtidos com a dieta contendo antibióticos, os valores de ED das dietas suplementadas com MOS ou MOS e CE foram superiores em até 7,25 e 7,39\%, com base na MS e MN, respectivamente.

Bactérias intestinais competem com o hospedeiro também por nutrientes fornecedores de energia, como o amido e os lipídios dietéticos (Ferket et al., 2002), e o fato de o MOS reduzir a carga bacteriana pela acidificação do lúmen intestinal (Zafar et al., 2004) é a provável razão da melhor ED de dietas suplementadas com MOS. Em estudo com perus, Ferket et al. (2002) observaram aumento de 3\% na EMA, atribuído à suplementação das dietas com MOS, o que diminuiu em $40 \%$ a produção de AGCC no jejuno, em decorrência da redução na produção do ácido propiônico, principal produto de fermentação de bactérias como as Bacteroides, que utilizam amido e açúcares como substratos primários.
Bedford \& Autio (1996) demonstraram que uma quantidade considerável de amido se encontra rodeada por uma parede celular intacta na digesta intestinal de aves alimentadas com dietas à base de trigo. $\mathrm{O}$ amido encapsulado pelos polissacarídeos da parede celular se torna menos disponível para digestão e, segundo Kocher et al. (2002), a liberação aumentada pelas enzimas exógenas de nutrientes encapsulados é um mecanismo para melhorar a utilização da energia dietética.

A interação MOS $\times$ CE foi significativa apenas para retenção de $\mathrm{P}(\mathrm{P}<0,03)$ (Tabela 4$)$, observando-se que o valor obtido com a dieta contendo MOS e CE foi superior ao dos demais tratamentos. A inclusão de MOS melhorou os coeficientes de digestibilidade ileal de $\mathrm{Ca}(\mathrm{P}<0,01)$ e $\mathrm{P}$ $(\mathrm{P}<0,01)$ e a retenção de $\mathrm{Ca}(\mathrm{P}<0,03)$. A interação controle positivo $\times$ fatorial $(\mathrm{P}<0,05)$ foi significativa para a retenção de Ca e P; os valores obtidos com as dietas contendo MOS e CE foram superiores em relação aos obtidos com a dieta contendo antibióticos.

Os melhores coeficientes de digestibilidade ileal de Ca e P e de retenção de Ca ocorreram porque os AGCC derivados da fermentação do MOS acidificam o meio, causando a solubilização de minerais como Ca e P e aumentando a altura e o perímetro de vilos e, conseqüentemente, a área de absorção. Há evidências de que o transporte para celular de Ca no intestino delgado seja aumentado com a adição de oligossacarídeos às dietas dos animais (Mineo et al., 
Tabela 3 - Energia digestível (ED) e energia metabolizável aparente (EMA) de dietas contendo MOS e/ou complexo enzimático (CE) com base na MS e na MN

Table 3 - Digestible (DE) and apparent metabolizable (AME) energy of diets containing MOS and/or enzymatic complex (EC), expressed on DM and as-fed basis (NM)

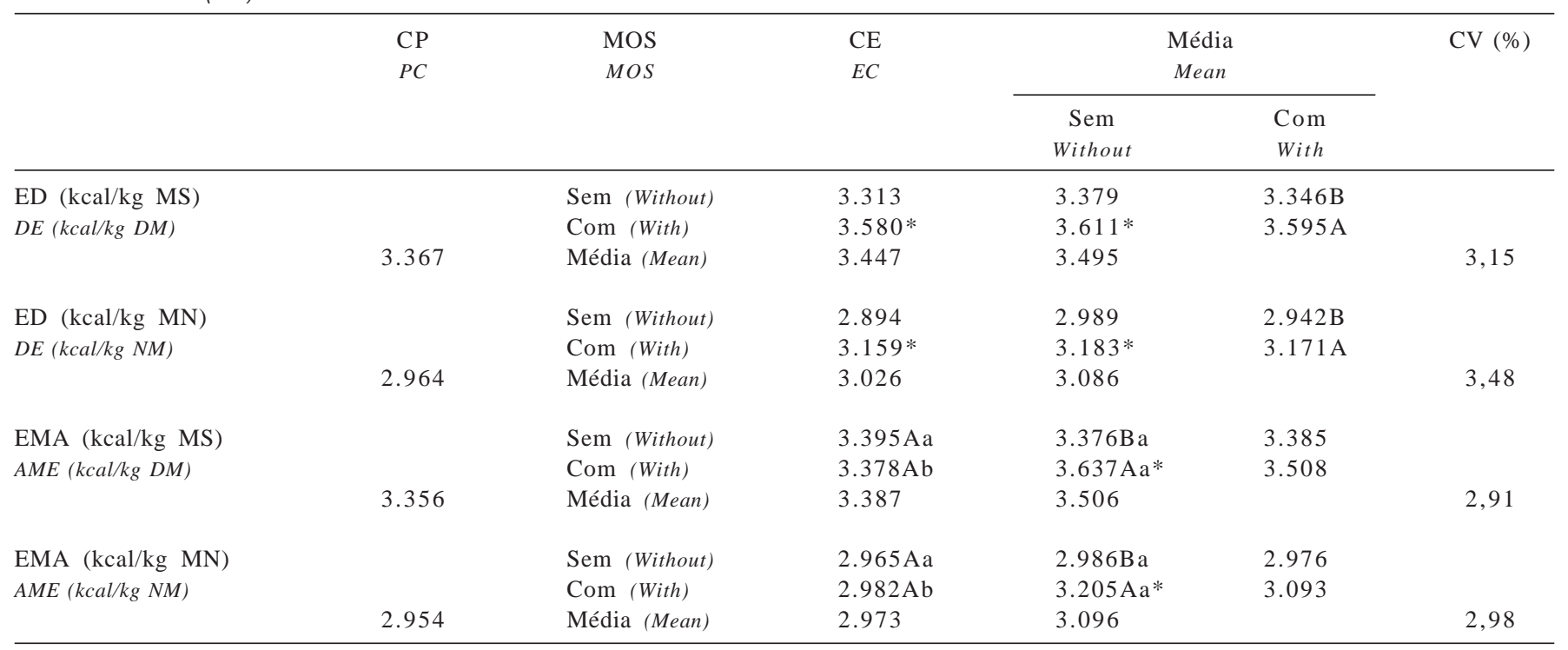

$\mathrm{CP}=$ controle positivo $(\mathrm{PC}=$ positive control).

Médias seguidas de letras diferentes minúsculas e maiúsculas nas linhas e colunas, respectivamente, diferem pelo teste Tukey.

*Difere do tratamento controle positivo pelo teste Dunnett.

Means followed by different small and capital letters in rows and columns, respectively, differ by Tukey test.

*Differ from positive control treatment by Dunnett test.

Tabela 4 - Retenção e coeficientes de digestibilidade aparente ileal de Ca e P em frangos de corte alimentados com dietas contendo mananoligossacarídeos (MOS) e/ou complexo enzimático (CE)

Table 4 - Retention and apparent ileal digestibility coefficients of Ca and P for broilers fed diets containing MOS and/or enzymatic complex

\begin{tabular}{|c|c|c|c|c|c|c|}
\hline & \multirow[t]{2}{*}{$\begin{array}{l}\mathrm{CP} \\
P C\end{array}$} & \multirow[t]{2}{*}{$\begin{array}{l}\text { MOS } \\
\text { MOS }\end{array}$} & \multirow[t]{2}{*}{$\begin{array}{l}\mathrm{CE} \\
\mathrm{EC}\end{array}$} & \multicolumn{2}{|c|}{$\begin{array}{l}\text { Média } \\
\text { Mean }\end{array}$} & \multirow[t]{2}{*}{ CV (\%) } \\
\hline & & & & $\begin{array}{c}\text { Sem } \\
\text { Without }\end{array}$ & $\begin{array}{l}\text { Com } \\
\text { With }\end{array}$ & \\
\hline Retenção de Ca (\%) & & Sem (Without) & 60,11 & 59,79 & $59,95 \mathrm{~B}$ & \\
\hline \multirow[t]{2}{*}{ Ca retention } & & Com (With) & 62,01 & $66,77^{*}$ & $64,39 \mathrm{~A}$ & \\
\hline & 59,32 & Média (Mean) & 61,06 & 63,28 & & 5,78 \\
\hline \multirow{3}{*}{$\begin{array}{l}\text { Coeficiente de digestilidade ileal do } \mathrm{Ca}(\%) \\
\text { Ileal digestibility coefficient of } \mathrm{Ca}\end{array}$} & & Sem (Without) & 55,49 & 59,11 & $57,30 \mathrm{~B}$ & \\
\hline & & Com (With) & 64,08 & 65,32 & $64,70 \mathrm{~A}$ & \\
\hline & 57,30 & Média (Mean) & 59,78 & 62,22 & & 9,55 \\
\hline \multirow{3}{*}{$\begin{array}{l}\text { Retenção de } \mathrm{P}(\%) \\
P \text { retention }\end{array}$} & & Sem (Without) & $61,11 \mathrm{Aa}$ & $59,95 \mathrm{Ba}$ & 60,53 & \\
\hline & & Com (With) & $62,04 \mathrm{Ab}$ & $69,57 \mathrm{Aa}^{*}$ & 65,81 & \\
\hline & 60,49 & Média (Mean) & 61,57 & 64,76 & & 5,53 \\
\hline \multirow{3}{*}{$\begin{array}{l}\text { Coeficiente de digestilidade ileal do } \mathrm{P}(\%) \\
\text { Ileal digestibility coefficient of } \mathrm{P}(\%)\end{array}$} & & Sem (Without) & 57,04 & 59,02 & $58,03 \mathrm{~B}$ & \\
\hline & & Com (With) & 64,02 & 67,42 & $65,72 \mathrm{~A}$ & \\
\hline & 59,67 & Média (Mean) & 60,53 & 63,22 & & 7,62 \\
\hline
\end{tabular}

$\mathrm{CP}=$ controle positivo $(\mathrm{PC}=$ positive control).

Médias seguidas de letras diferentes minúsculas e maiúsculas nas linhas e colunas, respectivamente, diferem pelo teste Tukey.

*Difere do tratamento controle positivo pelo teste Dunnett.

Means followed by different small and capital letters in rows and columns, respectively, differ by Tukey test.

*Differ from positive control treatment by Dunnett test.

2002; Suzuki \& Hara, 2004; Hara \& Kondo, 2005). Os PNA, mesmo não-viscosos, estão relacionados a falhas na absorção de minerais no intestino delgado em decorrência do seqüestro de cátions, causada pela presença de cargas negativas em suas estruturas (Camiruaga et al., 2001). Os minerais que se encontram fortemente associados à parede celular das plantas podem ser liberados pela quebra microbiana destes complexos polissacarídicos no intestino 
grosso (Lopez et al., 1998) ou pela adição de enzimas que degradam a parede celular.

Nas aves alimentadas com dietas contendo antibióticos, a digestibilidade ileal da MS e a retenção da MS, PB, Ca e P, assim como os valores de ED e EMA, foram inferiores $(\mathrm{P}<0,05)$ aos obtidos com dietas suplementadas com MOS e/ou CE.

Segundo Bongaerts et al. (2005), o uso de antibióticos por tempo prolongado promove a seleção de bactérias resistentes. $\mathrm{O} \mathrm{pH}$ alto das porções finais do intestino delgado propicia um meio adequado para a proliferação das bactérias produtoras de amônia que se tornaram resistentes. A amônia danifica a mucosa intestinal, diminuindo sua capacidade absortiva. Algumas bactérias têm também a capacidade de desconjugar ácidos biliares no intestino delgado (Silva \& Smithard, 2002) e interferiram na digestibilidade de lipídios. Como os antibióticos atuam sobre bactérias em geral, benéficas ou não (Ferket et al., 2002), é possível que tenha ocorrido desequilíbrio da microflora intestinal com reduzida concentração de lactobacilos e bifidobactérias, em comparação às dietas contendo MOS e/ou CE. O MOS, além de reduzir a quantidade de bactérias que proliferam em meio alcalino, estimula a proliferação de lactobacilos e bifidobactérias (Fernandez et al., 2002), consideradas benéficas por produzirem AGCC que estimulam o epitélio intestinal, entre outros efeitos. Assim, a menor utilização de nutrientes em aves alimentadas com as dietas com antibióticos foi ocasionada, provavelmente, pela maior competição entre bactérias e hospedeiro, pela menor capacidade absortiva da mucosa e pelo $\mathrm{pH}$ alcalino, em virtude da aumentada carga bacteriana. De acordo com Zafar et al. (2004), o pH alcalino diminui a solubilização dos minerais no intestino dificultando sua absorção. Quanto à ED e EMA, é possível que tenha ocorrido também redução da concentração e recirculação dos ácidos biliares nestas aves, promovendo redução da digestibilidade e metabolização da energia da dieta controle (Knarreborg et al., 2002).

\section{Conclusões}

A inclusão de mananoligossacarídeos e complexo enzimático às dietas, de forma isolada ou em conjunto, melhorou a digestibilidade ileal e a retenção de MS, PB, cálcio e fósforo e os valores de energia digestível e de metabolizável de dietas para frangos de corte.

\section{Agradecimento}

À Agroceres Nutrição Animal, pelas análises de P e Ca das dietas, digestas e das excretas.

\section{Literatura Citada}

BEDFORD, M.R.; AUTIO, K. Microscopic examination of feed and digesta from wheat-fed broiler chickens and its relation to bird performance. Poultry Science, v.75, n.1, p.1-14, 1996.

BONGAERTS, G.; SEVERIJNEN, R.; TIMMERMAN, H. Effect of antibiotics, prebiotics and probiotics in treatment for hepatic encephalopathy. Medical Hypotheses, v.64, n.1, p.64-68, 2005.

CAMIRUAGA, M.; GARCIA, F.; ELERA, R. et al. Respuesta productiva de pollos broilers a la adición de enzimas exógenas a dietas basadas en maíz o triticale. Ciência y Investigación Agraria, v.28, n.1, p.23-36, 2001.

CHOCT, M. Enzyme supplementation of poultry diets based on viscous cereals. In: BEDFORD, M.R.; PARTRIDGE, G.G. (Eds.) Enzymes in farm animal nutrition. Oxfordshire: Cab Publishing, 2001. 406p.

DILGER, R.N.; ONYANGO, E.M.; SANDS, J.S. et al. Evaluation of microbial phytase in broiler diets. Poultry Science, v.83, n.6, p.962-970, 2004

FERKET, P.R. Alternatives to antibiotics in poultry production: responses, practical experience and recommendations. In: ALLTECH'S ANNUAL SYMPOSIUM, 20., 2004, Lexington. Proceedings... Lexington: Alltech, 2004. p.54-67.

FERKET, P.R.; PARKS, C.W.; GRIMES, J.L. Benefits of dietary antibiotic and mannanoligosaccharide supplementation for poultry. In: MULTI-STATE POULTRY FEEDING AND NUTRITION CONFERENCE, 2002, Indianapolis. Proceedings... Indianapolis: University of Illinois, 2002. 22p.

FERNANDEZ, F.; HINTON, M.; Van GILS, B. Dietary mannanoligosaccharides and their effect on chicken caecal microflora in relation to Salmonella enteritidis colonization. Avian Pathology, v.31, n.1, p.49-58, 2002.

GARCÍA, M.C.; CARRILLO, G.R.R.; MARTÍNEZ, A.P. et al. Disponibilidad del fósforo de la pasta de soya y sorgo-gluten de maíz, adicionadas con fitasa en pollos de engorda en iniciación. Técnica Pecuária de México, v.41, n.3, p.295306, 2003.

HARA, H.; KONDO, K. Difructose anhydrides III and IV equally promote calcium absorption from the luminally perfused rat small intestine. Bioscience, Biotechnology, and Biochemistry, v.69, n.4, p.839-841, 2005.

HONG, D.; BURROWS, H.; ADEOLA, O. Addition of enzyme to starter and grower diets for ducks. Poultry Science, v.81, n.12, p.1842-1849, 2002.

JÓZEFIAK, D.; RUTKOWSKI, A.; MARTIN, S.A. Carbohydrate fermentation in the avian ceca: a review. Animal Feed Science and Technology, v.113, n.1, p.1-15, 2004.

KIRKPINAR, F.; AÇIKGÖZ, Z.; BOZKURT, M. et al. Effects of inclusion of poultry by-product meal and enzyme-prebiotic supplementation in grower diets on performance and feed digestibility of broilers. British Poultry Science, v.45, n.2, p.273-279, 2004.

KNARREBORG, A.; SIMON, M.A.; ENGBERG, R.M. et al. Effects of dietary fat source and subtherapeutic levels of antibiotic on the bacterial community in the ileum of broiler chickens at various ages. Applied and Environmental Microbiology, v.68, n.12, p.5918-5924, 2002.

KOBAYASHI, T.; MURAI, A.; OKADA, T. et al. Influence of dietary phosphorus level on growth performance in chicks given cornsoybean diet supplemented with amylase and acid protease. Animal Science Journal, v.73, n.3, p.215-220, 2002.

KOCHER, A.; CHOCT, M.; PORTER, M.D. et al. Effects of feed enzymes on nutritive value of soybean meal fed to broilers. British Poultry Science, v.43, n.1, p.54-63, 2002.

KUMPRECHT, I.; ZOBAC, P. The effect of mannan-oligosaccharides in feed mixtures on the performance of chicken broilers. Zivocisna Výroba, v.42, n.3, p.117-124, 1997. 
LOPEZ, H.W.; COULDRAY, C.; BELLANGER, J. et al. Intestinal fermentation lessens the inhibitory effects of phytic acid on mineral utilization in rats. Journal of Nutrition, v.128, n.7, p.1192-1198, 1998.

LYAYI, E.A.; DAVIES, B.I. Effect of enzyme supplementation of palm kernel meal and brewer's dried grain on the performance of broilers. International Journal of Poultry Science, v.4, n.2, p.76-80, 2005.

MENG, X.; SLOMINSKI, B.A.; GUENTER, W. The effect of fat type, carbohydrase, and lipase addition on growth performance and nutrient utilization of young broilers fed wheat-based diets. Poultry Science, v.83, n.10, p.1718-1727, 2004.

MENG, X.; SLOMINSKI, B.A.; NYACHOTI, C.M. et al. Degradation of cell wall polysaccharides by combinations of carbohydrase enzymes and their effect on nutrient utilization and broiler chicken performance. Poultry Science, v.84, n.1, p.37-47, 2005.

MINEO, H.; HARA, H.; SHIGEMATSU, N. Melibiose, difructose anhydride III and difructose anhydride IV enhance net calcium absorption in rat small and large intestinal epithelium by increasing the passage of tight junctions in vitro. The Journal of Nutrition, v.132, n.11, p.3394-3399, 2002.

MORAN, C.A. Functional components of the cell wall of Saccharomyces cerevisiae: applications for yeast glucan and mannan. In: INTERNATIONAL FEED INDUSTRY SYMPOSIUM, 20., 2004, Lexington. Proceedings... Lexington: Alltech, 2004. p. 280-296.

NOY, Y.; SKLAN, D. Digestion and absorption in the young chicks. Poultry Science, v.74, n.2, p.366-373, 1995.

RODRIGUES, P.B.; ROSTAGNO, H.S.; ALBINO, L.F.T. et al. Desempenho de frangos de corte, digestibilidade de nutrientes e valores energéticos de rações formuladas com vários milhos, suplementadas com enzimas. Revista Brasileira de Zootecnia, v.32, n.1, p.171-182, 2003.

ROSTAGnO, H.S.; ALBINO, L.F.T.; DONZELE, J.L. et al. Tabelas brasileiras para aves e suínos. Composição de alimentos e exigências nutricionais. Viçosa, MG: Universidade Federal de Viçosa, 2000. 141p.
SANTOS JR., A.A.; FERKET, P.R.; GRIMES, J.L. et al. Dietary pentosanase supplementation of diets containing different qualities of wheat on growth performance and metabolizable energy of turkey poults. International Journal of Poultry Science, v.3, n.1, p.33-45, 2004.

SILVA, D.J.; QUEIROZ, C.A. Análise de alimentos: métodos químicos e biológicos. 3.ed. Viçosa, MG: Editora UFV, 2002. $235 p$.

SILVA, S.S.P.; SMITHARD, R.R. Effect of enzyme supplementation of a rye-based diet on xylanase activity in the small intestine of broilers, on intestinal crypt cell proliferation and on nutrient digestibility and growth performance of the birds. British Poultry Science, v.43, n.2, p.274-282, 2002.

STATSOFT. Statistica for Windows (Computer program manual). Tulsa, 1995. (CD-ROM).

SUZUKI, T.; HARA, H. Various non-digestible saccharides increase intracellular calcium ion concentration in rat smallintestinal enterocytes. British Journal of Nutrition, v.92, n.5, p.751-755, 2004.

UNIVERSIDADE FEDERAL DE VIÇOSA - UFV. SAEG - Sistema de análises estatísticas e genéticas. Versão 8.0. Viçosa, MG, 2001. 150p. (Manual do usuário).

UNI, Z.; NOY, Y.; SKLAN, D. Posthatch changes in morphology and function of the small intestines in heavy and light strain chicks. Poultry Science, v.74, n.12, p.1622-1629, 1995.

ZAFAR, T.A.; WEAVER, C.M.; ZHAO, Y. et al. Nondigestible oligosaccharides increase calcium absorption and suppress bone resorption in ovariectomized rats. Journal of Nutrition, v.134, n.2, p.399-402, 2004.

ZDUNCZYK, Z.; JANKOWSKI, J.; JUSKIEWICZ, J. et al. Response of young turkeys to diets containing flavomycin, mannanoligosaccharide or inulin. Veterinarija ir Zootechnika, v.25, n.47, p.94-96, 2004. 